\title{
EDUCATION PROCESS VISUALIZATION IN METACOGNITION DEVELOPMENT AND SUSTAINABILITY
}

Dr. Elena Aleksandrovna Makarova, Taganrog Institute of Management and Economics, Taganrog, Russian Federation

E-mail: helen_makarova@mail.ru

Dr. Elena Lvovna Makarova, Southern Federal University, Russian Federation

E-mail: elmakarova@sfedu.ru

Dr. Anna Mikhailovna Varaksa, Novosibirsk State University of Economics and Management, Russian Federation

E-mail: anny.v@rambler.ru

\section{A R T I C L E I N F O}

Original Research

Received: October, 18.2017.

Revised: December, 05.2017.

Accepted: December, 07.2017.

doi:10.5937/IJCRSEE1702065A

\section{UDK}

159.922 .72 .072

159.953.5.072

\section{Keywords:}

visualization, meta-cognition,

meta-cognitive awareness,

reflection,

visual thinking,

schema theory.

\begin{abstract}
A B S T R A C T
The article reflects on the role of visualization in education. Modern society is characterized by rapid growth of information that people have to process in order to maintain progress and sustainability in science and development of education. The amount of information is growing so quickly that a person is no longer able to perceive actual data about the outside world and process it using traditional methods. The basis of the "image of the world" contains not only concepts, but the semantic images created with the help of visual thinking. In our study we assume that students are quite limited in their knowledge about cognitive phenomena or in their meta-cognition and do relatively little monitoring of their own memory, comprehension, and other cognitive enterprises. But we also assume that every student is potentially capable of meta-cognition, which is thinking of how better to perform cognitive actions and to be aware of how to learn. Developing meta-cognitive awareness is important because it helps learners become more efficacious and more autonomous. For many of them it can be identified as the most effective way of acquiring knowledge. Visualizing the very process of learning can help see how well it is going. Schema theory offers different ways of using schemas, especially in education. So far, there have been researches on schema as a tool for particular skills such as better comprehension, memorizing and retrieval of the knowledge received. It means students can use schemas to better understand the process of learning and skills acquired.
\end{abstract}

(C) 2017 IJCRSEE. All rights reserved.

\section{INTRODUCTION}

Visualization involves the creation of real or unreal images in the mind's eye. It usually refers to visual images, sounds, movements, touch, taste and smell, in general, all the images that can be perceived by human senses or imagined by human mind.

Corresponding Author

Dr. Elena Aleksandrovna Makarova, Taganrog Institute of Management and Economics, Taganrog

E-mail: helen_makarova@mail.ru

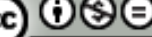

This work is licensed under a Creative Commons Attribution - NonCommercial - NoDerivs 4.0. The article is published with Open Access at www.ijcrsee.com
In Piaget's opinion, there is a possibility of the development of perception as a gradual activity for establishing relations between individual details of the sensory field. He shows that the child in his young age does not yet have a genuine perception of objects and space; he does not even differentiate objects and himself in the world without distinguishing the changes in the type of objects caused by his own movements, from changes that have arisen in result of the child's actions or objects movements. The constant character of the object appears as a consequence of the spatial field organization, in other words, the internal scheme of the immediate environment, of the world around, through which the child is able to anticipate the consequences of his own movements in the environment. Spa- 
tial field, in turn, is formed in connection with the coordination of the child's movements. Thus, the basis of perception is the internalized sensor-motor schemes of locomotion and manipulation of objects. As J. Piaget puts it, "knowledge of the world is not discovered, but is created as an image". "The image is a subjective picture of the world or its fragments, the subjective representation of the objects of the external world, conditioned both by sensually perceived signs and hypothetical constructs" (Piaget, 1986). The image is a subjective phenomenon that arises as a result of objectively practical, sensory-perceptual, intellectual activity, which is a holistic integral reflection of reality, in which the main perceptual categories are space, movement, color, form, texture, sounds, etc. In the information sense, the image is an unusually capacious form of representation of the surrounding reality. Images are multidimensional, multi-categorical and poly-modal.

In the age of accelerated technological progress and digital gadgets the incoming information comes in the amounts that are impossible to process, exchange and memorize using traditional methods of education. Visualization is a holistic way to deal with the image of the world not divided into separate details and ideas, but with holistic visual images created via visual thinking and visual operations producing images easy to perceive and memorize. Visual images can range from detail graphic representations (such as pictures and photographs) to abstract schemes, diagrams, graphs and mind maps. Besides, visualization is connected with emotional sphere of a person: in order to be memorized visual images should be positive, not only perception of the reality around, but also visual thinking should become positive emotional experience.

Visually presented information can be read and interpreted as well as any verbal text. Modern students would not pay attention to boring, difficult to understand verbal texts, but rather be attracted by colored structural schemes and diagrams. After comparing different teaching technologies it is concluded that visual representation is more effective because of their structured and systematized form that makes it easy to teach and to learn. Such structures are kept in long-term memory and easily reached and actualized if necessary, thus contributing to memorizing a lot of information. Visualization in teaching is based on the special properties of mental images as objects of knowledge, expresses the degree of accessibility and clarity of these images for the subject. It relies on one of the most important principles of learning (the principle of clarity) (Makarova, 2016).

Mental images, often called "visualization or quasi-perceptual experience", resemble real perceptual experience, sometimes with the same emotional attitude, but arise in the absence of an appropriate perceptual stimulus. They are associated not with imagination and fantasy, but with cognitive functions such as memory, perception, reflection and thinking. Although mental images arise in all sensory modes, most works on philosophy, psychology and pedagogy are focused only on visual images leaving audio and tactile modes behind. Since the concept is more like a scheme, the human psyche is not an image, but a sense of the world created by the imagination of the subject and includes the person himself, other people, the spatial environment and the temporal sequence of events. Being the basis for the implementation of practical actions to master the external world, the image is also determined by the nature of these actions, during which the original image is modified, increasingly satisfying practical needs. In its intellectual development, the subject proceeds from a search of semantic, emotionally saturated and expressive action to the construction of the meaning, containing the prerequisites for modeling the world in its semantic perspective and semantic integrity. Semantic integrity is that ideal environment, the mental space within which all objects, qualities and properties of the material world are depicted from a certain point of view thus acquiring a certain meaning.

In this study trying to connect visualization to metacognition, we suppose that students mostly are not aware of many cognitive phenomena they encounter in the process of study, so they cannot monitor their advance in learning and success or control their comprehension and memorizing. In order to make students' learning more conscious we suggest to use visual tools for regulation of cognition, study progress and results of learning. This is how students get knowledge about the way they should plan their cognitive activities, implement metacognitive strategies into their learning process, comprehend, memorize, monitor and correct errors, assess progress and also evaluate their results. It means they stop being passive recipients of knowledge, but start to actively participate in planning, management and evaluation of knowledge acquisition. Aware students can understand what they are doing and how to better achieve de- 
sired result thus directly improving their performance.

Visual reality is presented as an informational construct, which must be 'readable' and can be interpreted in the same way as any verbal text. Visual reality has ceased to be perceived as a secondary or subordinate dimension; thinking and imagination collide in the semantic form. As a source for learning, visual material is unique in its cognitive potential and the multilevel information encoded in it. Comparative analysis of different ways of presenting information leads to conclusion that visual methods are more effective, since they present information in a more structured and systematized form, making it easy to comprehend and to memorize. Graphic representation helps visualize and understand the structure and sequence of information. With increased motivation to study, thinking becomes more flexible, so a student can get rid of typical stereotypes, turning dogmatic thinking into a critical and creative one. Images, representations and concepts unite in the meaning, giving way to logical thinking.

Visual thinking is thinking through visual operations, and so it allows using human ability to see and understand images, then to analyze data received. Accordingly, the task of visualization is the transformation of huge arrays of information into graphic images that are comprehensible to human perception when connected by a single meaning. Visual images can range from detailed graphic images to abstract structures, graphs, charts, diagrams, etc. This is how visualization is connected to meta-cognition which is "one's stored knowledge or beliefs about oneself and others as cognitive agents, about tasks, about actions or strategies, and about how all these interact to affect the outcomes of any sort of intellectual enterprise" (Flavell, 1979).

Visualization is a way of fixing and sharing information, not only complementary, but also serving as an alternative to undividedly prevailing verbal and written communication. At the present time, a 'copying of cultural environment' is under way, in which all the achievements of mankind, fully reflected in the written texts before, receive an audiovisual expression. Visualization in comparison with verbal communication is psychologically more capacious and easy, socially - more massive and accessible, but less stable and unidirectional way of structuring knowledge. "Meaningful teaching and learning experiences should provide equitable, authentic learning opportunities. Today's increasingly diverse students seek alternative ways to complete tasks, often utilizing technology. Immersive learning experiences can provide real-life contexts for training and deeper conceptual thinking. ...The use of immersive visualization should support equity, engagement and learning" (Schaffer, 2017). These features of visualization form its socio-cultural and cognitive functions. In the communicative function, visualization quickly becomes the leading medium of mass communication, assuming the associated social and regulatory duties. Throughout the world, there is a gradual shift from the verbal component to the visual: the visual images have such an influence that people are becoming less able to perceive the printed word; they cannot concentrate their attention on the verbal text for a long period of time. We can say that visualization penetrates into all spheres of human life and activity.

With the methodically competent use of visualization methods, students can not only plan their own education process, evaluating results and monitoring progress, but also make transition to higher levels of cognitive activity, mastering the subject content as well. In the process of implementation of visualization methods in teaching, it is necessary to take into account the psychological features of the cognitive mechanisms activity. Metacognition helps students to become aware of the correlation of the word and image in the visual material, of the very concept "metacognition", to properly organize and plan their learning, to evaluation results and progress assessment. Meta-cognition has been defined by Schraw and Dennison as the "ability to reflect on, understand, and control one's learning" (Schraw and Dennison 1994). As Flavell put it, "meta-cognitive experiences are conscious cognitive or affective experiences that occur during the enterprise and concern any aspect of it - often, how well it is going. Research is needed to describe and explain spontaneous developmental acquisitions in this area and find effective ways of teaching meta-cognitive knowledge and cognitive monitoring skills" (Flavell, 1979).

Visual methods in teaching allow solving various developmental problems: the development of observation, visual memory, imaginative thinking, also decision making abilities. The visual image creates the prerequisites for the development of left- and righthemispheric mental processes. Text thinking is performed by the left hemisphere, which is associated with rational behavior. Visual thinking is carried out by the right hemisphere, 
which is closer to the irrational thinking. But both hemispheres contribute to meta-cognitive thinking development and to successful learning and practical application of knowledge to problem solution and decision making processes (see Fig. 1).

Initially studied for its development in children (Baker and Brown 1984; Flavell, 1979), "focusing on both the fascinating nature of children's thinking and the excitement and change in this area, using an integrated topical approach", the studies explored the developmental aspects of social cognition, perception, memory, and language. Theoretically balanced, they considered the full spectrum of approaches-from Piaget's developmental stages, to information-processing (including connectionism), dynamic systems, contextual, theory-change, neo-Piagetian, evolutionary, neuroscience, and constraint approaches. Later, researchers began to look at how experts display meta-cognitive thinking and how, then, these thought processes can be taught to novices to improve their learning (Abdellah, 2015; Jiang, Lin, Liang, 2016; Saenz, Geraci, Miller, Tirso, 2017).

\section{MATERIALS AND METHODS}

This study investigated the effect of visualization on meta-cognition and academic performance among students of Taganrog Institute of Management and Economics using a mixed method approach. It also explored differences in meta-cognition between second language writing and second-language reading by students of different majors in law, economics, and management. A total of 238 college students studying English as a Second Language participated in the study. Quantitative data were collected from the Meta-cognitive Awareness Inventory, aptitude tests, achievement tests in ESL, problem solving assignments and schemas presentation and analysis. Qualitative data were collected using questionnaires and interviews. The mixed-method study consisted of a test approach interviews and students' individual schemas representing significant differences in meta-cognition at the beginning and at the end of experimental course of ESL. Block diagrams, graph schemes, logical-semantic models - visual representations of knowledge are the equivalents of cognition and together they constitute the so-called visual plan of meta-cognitive thinking. The main role here is played by students' intellectual resources, formed as mental structures.

Reading was based on the professional thesaurus in different disciplines; comprehension was checked with the help of multiple choice tests. In order to monitor students' problem solving abilities case method was used.

Quantitative data were analyzed using statistics and represented in charts and diagrams. Qualitative data were analyzed, categorized and also visually displayed. Although $52 \%$ of female and $48 \%$ of male students took part in experimental learning and outperformed male students on problem solving tests, gender effects were not noted in the research. At the beginning of the experiment highly efficacious students did better on the tests and performed more successfully on problem solving assignments than less efficacious students.

For the goals of the experiment writing of the academic essay was chosen as this writing experience elicited greater meta-cognition than short story writing and became more professionally useful for college students of different majors. Besides writing an essay is a comparatively new kind of writing for Russian students demanding less emotional, but more professionally creative writing strategies to become successful. In the experiment students had to plan and foster their metacognition and awareness, monitor the writing process, be aware of academic word choice, assess quality of writing, consider grammar and style, follow instructions to comply with the task requirements. Meta-cognitive strategies help provide psychologically comfortable teaching and learning environment and sustainable development of ESL reading and listening skills, also promoting writing skills and problem solving decision making abilities.

\section{RESULTS}

This study aims to investigate the relationship between visualization and meta-cognitive strategies the integration of which can lead to development of a trainee's reflective thinking and meta-cognition skills. The study was applied on 238 students of Taganrog Institute of Management and Economics majoring in law, economics and management. Schema theory was applied in English as a Second Language classes as English is included in all students' schedules. There are equal requirements as to grammar, vocabulary, text and listening comprehension, so the emphasis of the 
study is put on meta-cognition development as well as knowledge management skills, good planning skills, reflective thinking and results evaluation.

"A person's ability to control a wide variety of cognitive enterprises depends on the actions and interactions among these components" (Mevarech and Karmarski, 1997).

In the course of experimental leaning Meta-cognitive Awareness Inventory (Schraw and Dennison 1994) for a quick assessment of meta-cognitive skills, planning, information management, monitoring, debugging, assessment or evaluation strategies was administered twice to the same groups of students at the beginning and at the end of the course of studies. This inventory measures different components of meta-cognition (e.g. procedural, declarative, and conditional knowledge of cognition; and aspects of regulation of cognition, like planning, monitoring, debugging, etc.), also the levels of students' reflective thinking (feeling - description - analysis - action plan - evaluation - conclusion) can be identified. According to the Inventory we split meta-cognition into two categories: knowledge and regulation, relating both to strengths of meta-cognition and performance results. Meta-cognitively aware students were able to self-assess their abilities and to plan their learning activities accordingly to implement them into problem solution/decision making.

Comparing learning to research in experimental course of studies, we could see that students think meta-cognitively all the time, reflecting on their current understanding of information, on the research questions posed, and their thinking changing with new information acquisition. Showing students how to think procedurally in solving problems $\backslash$ decision making teachers demonstrate and students learn where to start, what to do first and next, how to check and evaluate the correctness of their solution, how to know what is done and whether it is done right - it is one example of meta-cognitive modeling. As it came the results before and after metacognitive skills development show clear differences in the students' grades on the test and their performance in class.
Table 1. Meta-cognition awareness development (at the beginning of the experimental learning)

\begin{tabular}{lc}
\hline 1. Meta-cognitive skills developed & Percent \\
\hline Declarative knowledge & $\mathbf{8 7 \%}$ \\
\hline Procedural knowledge & $\mathbf{6 7 \%}$ \\
\hline Conditional knowledge & $\mathbf{5 7 \%}$ \\
\hline 2. Regulation of cognition & \\
\hline Planning & $\mathbf{8 9 \%}$ \\
\hline Information management strategies & $\mathbf{5 4 \%}$ \\
\hline Comprehension monitoring & $\mathbf{5 2 \%}$ \\
\hline Debugging strategies & $\mathbf{2 7 \%}$ \\
\hline Control & $\mathbf{4 5 \%}$ \\
\hline Evaluation & $\mathbf{2 4 \%}$ \\
\hline
\end{tabular}

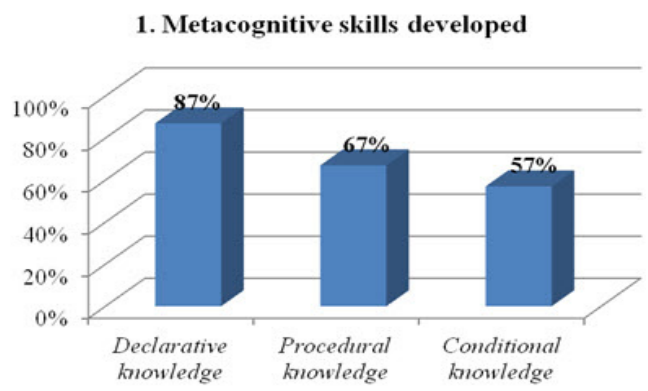

2. Regulation of cognition

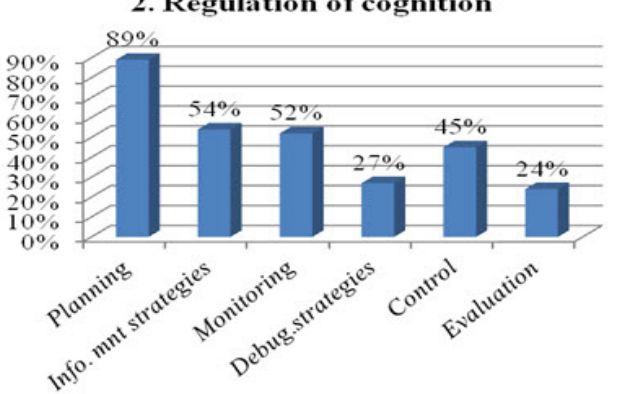

Figure 1. Meta-cognition awareness development (at the beginning of the experimental learning)

Table 2. Meta-cognition awareness development (at the end of the experimental learning)

\begin{tabular}{lc}
\hline 1. Meta-cognitive skills developed & Percent \\
\hline Declarative knowledge & $\mathbf{9 2 \%}$ \\
\hline Procedural knowledge & $\mathbf{7 8 \%}$ \\
\hline Conditional knowledge & $59 \%$ \\
\hline 2. Regulation of cognition & \\
\hline Planning & $\mathbf{9 0 \%}$ \\
\hline Information management strategies & $\mathbf{4 8 \%}$ \\
\hline Comprehension monitoring & $\mathbf{6 9 \%}$ \\
\hline Debugging strategies & $\mathbf{5 4 \%}$ \\
\hline Evaluation & $\mathbf{3 5 \%}$ \\
\hline
\end{tabular}




\section{Metacognitive skills developed}

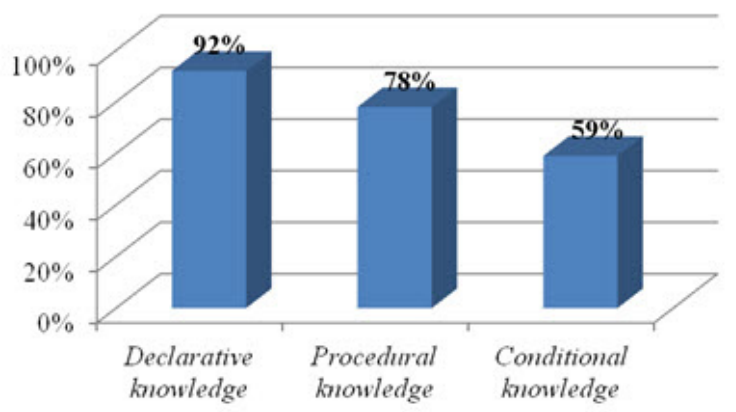

2. Regulation of cognition

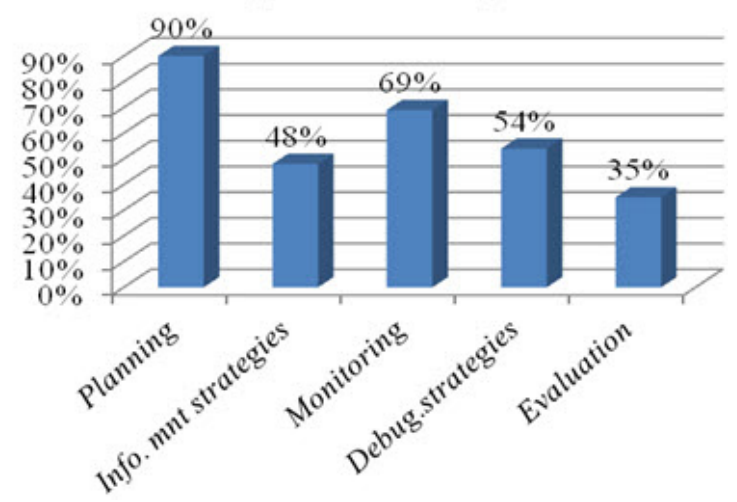

Figure 2. Meta-cognition awareness development (at the end of the experimental learning)

According to the results of the experiment, a statistical hypothesis was put forward about the significance of the discrepancies between the initial and final results of the experiment, the reliability of the results is confirmed by Fisher's angular transformation $\left(\varphi^{*} ; \mathrm{P}\right)$.

In general, the experimental groups differed significantly in the results of the main assessments, which is indicative of the effectiveness of the experimental work and the chosen author's strategy of the organization of metacognition awareness development technology.

In Section 1, students' meta-cognitive skills development is demonstrated. With declarative knowledge of about $90 \%$ students usually obtain knowledge via discussions, presentations, demonstrations, but need to learn how to process knowledge for practical application or to use critical thinking to assess and evaluate their results.

With procedural knowledge of about $70 \%$ students understand the very process of learning as well as the possibility of knowledge practical application in various situations, so they obtain knowledge via cooperative learning, team-work, problem solving activities and discovery.

With conditional knowledge of about
$60 \%$ students obtain knowledge via problem situation modeling, they know when, why and how to use meta-cognitive strategies.

In section 2, Regulation of cognition is displayed. With planning of about $90 \%$ students plan their cognitive activity, consider several ways to solve a problem and choose the best one.

With information management strategies of about $50 \%$ students use selective focusing to choose among their learning skills, organize and sequence them in order to process information more efficiently, summarize and elaborate details of the problem to be solved or decision to be made.

With comprehension monitoring of about $70 \%$ students use self-assessment strategies to check their comprehension, make sure they understand concepts, their relations and options when solving a problem or making a decision.

With debugging strategies of about $60 \%$ students evaluate their learning and learning strategies used in order to find and correct errors in comprehension and performance.

With evaluation of about $30-35 \%$ students analyze every learning episode and meta-cognitive strategy effectiveness, assess their performance when solving a problem and make a decision.

The first stage of the experiment included studies of students' cognitive control. At this stage, students' own knowledge and thinking processes and how they can control both of them are studied. Within this stage the accuracy of the prediction, effort and the distribution of attention are assessed. Oral reports of the students during this stage allowed determining what knowledge an individual derived from memory for solving the problem.

The second stage included studies of self-regulation of cognition (thinking and reflection). Usually, problem solutionldecision making requires knowledge transfer and strategy choice. In general the procedure is choosing strategies for performing a specific task. Once students demonstrate an understanding of the strategy, they are given a task, different from the first, but structurally equivalent to it. So students need knowledge and strategies transfer, but have to decide whether to use this strategy as it is or change it according to the new task. Another possibility is to abandon it in favor of another strategy that could be used to solve a new problem.

The third stage included control and regulatory studies in which students control available information in the process of think- 
ing and then use this information to regulate other learning processes. Reflection is also included in this stage.

Finally, the fourth stage of the metacognitive study included practical application of information obtained and strategies mastered to different problem solutions or decision making. Students answered a very important and fundamental question - whether or not their learning outcomes improved with the help of meta-cognitive processes.

Metacognitive processes include planning, strategy choice, conscious control over the learning process, mistakes correction, analysis of cognitive strategy efficiency, and change of cognitive behavior when necessary. All of these can be packed into 4 structures; goal setting, its achievement support, schedule compilation and results control.

Experimental program was aimed at students' self-regulation of their cognitive activity at three levels: cognitive, metacognitive and intentional. Cognitive experience was based on mental structure providing storage, ordering and transformation of existing knowledge. Metacognitive experience was aimed at finding a suitable niche for the new knowledge in already existing blocks of information, providing control over individual intellectual resources, thus regulating intellectual activity. Intellectual activity regulation requires:

1. ability to plan cognitive activity,

2. ability to predict results and their consequences,

3. ability to assess results of cognitive activity,

4. ability to choose and modify cognitive strategies.

In our experiment, qualitative data were collected as students went through their cognitive activity. The results of students' metacognitive activity: goal setting, its achievement support, schedule compilation and results control were checked. The given processes require reflection, so the Berezhnova L.N. test "Selfdevelopment reflection" was used to define the level of self-development, self-evaluation of achievements and also assessment of potential and abilities for future development.

Also Achievement Tests and Aptitude Tests were used to measure students' development and results of their learning. Aptitude Test contained Numerical Reasoning, Verbal Reasoning, Diagrammic Reasoning and Situational Judgment sections.

\section{DISCUSSIONS}

Despite the increasing use of didactic means, which involve combining information impact on various human senses and on the ways of presentation of educational information, the leading type of perception of information when working with various teaching aids is visual, which involves the development of both traditionally visual and innovative learning means and techniques, allowing to activate the work of vision in the learning process. Gradually, the need for innovation becomes more and more obvious, and requires an early understanding. We need new didactic principles based on information technology, and a new didactics, based on the formation of meaning patterns for creating the "metacognitive prompt" of the trainee. Using the enormous capabilities of the visual analyzer when visualizing educational information requires taking into account the laws of visual perception, the competent use of visual methods in teaching and the role of meta-cognition in developing conscious and aware learning. Therefore, with special structuring, coding and presentation of the material, with the help of visualization tools and meta-cognitive strategies, large amounts of information can be transmitted in a collapsed form, and cognitive mechanisms that supplement the verbal channel of information entry can be updated. The following structured information matrixes are a new generation of learning materials, in which the image and text are combined organically, mutually reinforcing each other. The main idea of such materials is to convey the idea in the unity of the image and the text, proceeding from the thesis that the figurative and verbal components of thinking are much stronger in unity.

The creation of meta-cognitive schemas should be the person's cognitive task planning, in which, along with the sensation, memory, thinking, imagination, personal meaning, meta-cognitive strategies participate as well. Any external reality is reflected in the framework of some model in the inner world of the person, created with the help of specific activity, expressed in the process of perception. All the information perceived from the outside is received first in the form of separate primary sensations, but everything that he sees, hears, feels, is refracted through the prism of comprehension and awareness, and only then becomes a mental construct, an image of reality which can be interiorized (see Table 3). 
(IJCRSEE) International Journal of Cognitive Research in Science, Engineering and Education Vol. 5, No. 2, 2017.

Table 3. Self-assessment guide promot-ing students' meta-cognition

\begin{tabular}{llll}
\hline \multicolumn{1}{c}{ Activity } & \multicolumn{1}{c}{ Planning } & \multicolumn{1}{c}{ Monitoring } & \multicolumn{1}{c}{ Evaluation } \\
\hline $\begin{array}{l}\text { Brainstorming } \\
\text { session }\end{array}$ & $\begin{array}{l}\text { What are concepts } \\
\text { involved in the problem? }\end{array}$ & $\begin{array}{l}\text { Do I need all the words on a } \\
\text { brainstorming list? }\end{array}$ & $\begin{array}{l}\text { Is my focusing on the } \\
\text { problem accurate? }\end{array}$ \\
\hline $\begin{array}{l}\text { Problem situation } \\
\text { modeling }\end{array}$ & $\begin{array}{l}\text { How does it relate to what } \\
\text { I already know? }\end{array}$ & $\begin{array}{l}\text { Is the model facilitating problem } \\
\text { solutionldecision making? }\end{array}$ & $\begin{array}{l}\text { Is this material personally } \\
\text { relevant? }\end{array}$ \\
\hline $\begin{array}{l}\text { Discussion } \\
\text { Reflective }\end{array}$ & $\begin{array}{l}\text { What else can I do to } \\
\text { improve problem solution? }\end{array}$ & $\begin{array}{l}\text { Do I need to change my learning } \\
\text { strategies? }\end{array}$ & Is this approach efficient? \\
\hline Whinking & What are my assumptions? & $\begin{array}{l}\text { What is impeding learning and } \\
\text { problem solution? }\end{array}$ & $\begin{array}{l}\text { What mistakes have I } \\
\text { made? How do they affect } \\
\text { problem solution? }\end{array}$ \\
\hline Essay writing & $\begin{array}{l}\text { What parts do I need in my } \\
\text { essay? }\end{array}$ & $\begin{array}{l}\text { Am I describing my learning } \\
\text { activities in full? }\end{array}$ & $\begin{array}{l}\text { Are the learning strategies } \\
\text { facilitating learning? }\end{array}$ \\
\hline
\end{tabular}

There is close connection between external and internal means helping to explore and understand both the internal and external worlds of the individual. Any external means can be fixed in the form of images, models, descriptions, or can be internalized by actively reflecting them in person's consciousness. The internalized external means include many additional elements and connections between them, conditioned by knowledge, experience, features of the psyche and actualized mental processes of a student. The model of any external objects and activities can be represented as some internal images and schemas, the study of which serves as a means for obtaining knowledge in a certain sphere. The modeling method is based on visualization intended to foster meta-cognition awareness and to enhance students' learning. Visualization of educational content and meta-cognitive strategies should be adopted by a student and interiorized, which means presentation, structuring and designing educational knowledge in the information content of static (paper) or dynamic (multimedia) teaching and leaning aids.

Repeated testing with visualization support results in significantly greater retention of information taught in English language class. Testing in our study is considered as indispensable assessment device for its potential impact on students' self-evaluation (see Table 4).

Table 4. Repeated testing with visualization support results

\begin{tabular}{lcc}
\hline \multirow{2}{*}{$\begin{array}{c}\text { Knowledge and } \\
\text { regulation }\end{array}$} & \multicolumn{2}{c}{ Performance } \\
\cline { 2 - 3 } & Before & After \\
\hline Vocabulary & $22 \%$ & $63 \%$ \\
\hline Grammar & $18 \%$ & $44 \%$ \\
\hline $\begin{array}{l}\text { Listening compre- } \\
\text { hension }\end{array}$ & $19 \%$ & $23 \%$ \\
\hline $\begin{array}{l}\text { Reading compre- } \\
\text { hension }\end{array}$ & $49 \%$ & $74 \%$ \\
\hline Writing & $30 \%$ & $73 \%$ \\
\hline
\end{tabular}

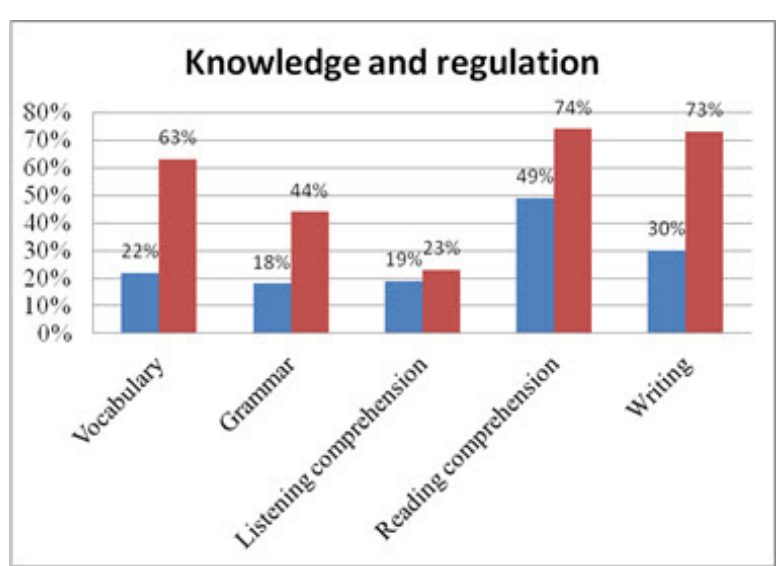

Figure 3. Repeated testing with visualization support results

In the study subjects of different majors were offered English language tests similar in form, but referring to different spheres of knowledge (Law, Economics, Management). The assumption was that performance won't depend on the nature of information, but on the meta-cognitive skills developed prior to test administering. Results of approbation proved our assumption, that is meta-cognitive abilities depend greatly on students' visualization of the learning process and on the type of instruction, providing intellectual development of students.

When the students moved along the schema and practiced problem situation modeling, decision evaluation, knowledge transfer and different levels of reflective thinking by writing brief essay of these reflections and discussed them through brain-storming sessions, it definitely had a direct impact on meta-cognition awareness development providing upgrade to the next education level. Meta-cognitive awareness also helps to promote knowledge transfer to other spheres of students' learning activities. 


\section{CONCLUSIONS}

When visualizing educational content and ways to comprehend and memorize it, it is necessary to take into account different personality traits, types of a trainee's cognitive ability, different types of leading sensory modalities, and undoubtedly abilities to be metacognitive about their learning. Visual methods in teaching, relying on the psychological characteristics of trainees, allow solving various developmental problems: the development of observation, visual memory, imaginative thinking, creativity, awareness, etc.

The thinking process with the use of meta-cognitive strategies visualization in training can also be strengthened by expanding the activated types of thinking. Along with the abstract-logical, visualization of information allows to include mechanisms of visualefficient, figurative, associative thinking, to strengthen the activity of imagination (reproductive and creative) (Makarova, Abakumova, Ermakov, 2006).

Scientific knowledge can become an integral part of mental content of a trainee only if it is internalized through the polymodal components of the cognitive mechanism - through the trainee's personal meanings. Only in this case, a trainee can comprehend not only sensibly perceived objects, but also things that are not observable in the actual perceptual space, but exit in general phenomenological theory.

This approach determines the view on thinking (meta-cognitive thinking), as the internal action, the activity of the mind, thanks to which it becomes possible to comprehend the connections and relations between the objects studied within the learning content in the modern educational space.

Introduction of meta-cognitive strategies into a trainee's learning activities is determined by the modern trends in education as the most acceptable and effective way of information perception, comprehension, processing and memorizing. In the practice of teaching, several areas of visualization of educational content and meta-cognitive strategies have been identified, which are examples of the organization of educational activities:

- presentation of new information as illustrations, in the form of diagrams, tables, graphs, drawings, graphic images, etc.;

- consolidation of the information in the form of text and graphic images, as well as systematization of computer graphic information;

- planning of learning activities, pacing the progress, anticipating the results in acquiring knowledge;

- preparing trainees for the preservation of information in the forms effective for perception, comprehension and memorizing;

- interpretation of information, transformation of educational content into schemes and cognitive constructs convenient for memorizing and retrievable if necessary.

With the help of visualization tools, meta-cognitive experience of a trainee can be used to manage educational activities, self-regulation and self-assessment in learning. Information processing using visual tools leads to certain mental constructs appearance in the learner's mind, they can be of different degrees of generalization: from detailed pictures to schemes, graphs, maps, diagrams, individual symbols, abstract signs. But the most important thing is that the new educational environment creates fundamentally new roles for the teacher (facilitator) and the learner (the independent researcher), and a new relationship between them.

Unfortunately, meta-cognitive awareness toward one's learning does not appear automatically or easily transfer from a teacher? It has to be taught. Student's self-analysis about learning and thinking could include: What assumptions do I hold about the problem and its solution? Do I have proof for those assumptions? Why do I make the decisions and how do I come up with them? What do I know about learning process? What would I like to learn? What am I confused about? These analyses can also become more specific to particular details, ranging from an individual class session to the scope of an entire course of studies.

The most general provisions of the concept of students' meta-cognition are: 1) knowledge of thinking process, motivational sphere and emotional states; 2) the ability to consciously and deliberately control and regulate their knowledge, the processes of thinking, of motivational and emotional states.

In the conclusion, we would like to emphasize that it is premature to consider that visualization (schemes, frames, gestalts and other images) can completely replace the verbal method of presenting information. However, visualization of the information content, giving it personal meaning and sensual experience, will allow to direct the thought in the required direction, pay attention to meta-cognitive awareness essential for understanding concepts and knowledge transfer, and most importantly, the integration of visual and ver- 
bal ways of presenting information will help students to comprehend the meaning of the reality around them and to build their own 'image of the world' adequate to this reality.

\section{ACKNOWLEDGEMENTS}

The authors express their gratitude to Taganrog Institute of Management and Economics for their assistance that made the following Project possible.

\section{Conflict of interests}

Authors declare no conflict of interest.

\section{REFERENCES}

Abdellah, R. (2015). Metacognitive Awareness and its Relation to Academic Achievement and Teaching Performance of Pre-service Female Teachers in Ajman University in UAE. Procedia - Social and Behavioral Sciences. 174,. 560-567. https:// doi.org/10.1016/j.sbspro.2015.01.707

Baker, L., Brown, A.L. (1984). Metacognitive Skills and Reading. In P. D. Pearson, R. Barr, M. L. Kamil \& P. Mosenthal (Eds.), Handbook of Reading Research, New York: Longman, 353394.

Flavell, J.H. (1971). First discussant's comments: What is memory development the development of? Human Development, 14, 272-278. https://doi. org/10.1159/000271221

Flavell, J.H. (1979). Metacognition and Cognitive Monitoring: A New Area of Cognitive-Developmental Inquiry. American Psychologist, 34(10), 906-911. $\quad$ http://dx.doi.org/10.1037/0003066X.34.10.906

Flavell, J.H. (1985). Cognitive development, PrenticeHall, 338.

Gall, M.D., Gall, J.P., Jacobsen, D.R., Bullock, T.L. (1990). Tools for Learning: A Guide to Teaching Study Skills. Alexandria, VA: Association for Supervision and Curriculum Development. http://files.eric.ed.gov/fulltext/ED320126.pdf

Jiang, Y., Lin M., Liang G.. (2016). Assessing teachers' metacognition in teaching: The Teacher Metacognition Inventory. Teaching and Teacher Education. 59, 403-413. https://doi.org/10.1016/j. tate.2016.07.014

Makarova, E.A. (2016). Visual culture in educational environment and innovative teaching technologies. Universal Journal of Management, $4(11), 621-627$ https://doi.org/10.13189/ ujm.2016.041104

Makarova, E.A., Abakumova, I.V., Ermakov, P.N. (2006). Skhema i fon: introyektsiya v neod-norodnom semioticheskom prostranstve [Scheme and background: introjection in heterogeneous semiotic space]. - Moscow: CREDO. 175.

Mevarech, Z. R., \& Karmarski, B. (1997). Improve: A multidimensional method for teaching mathematics in heterogeneous classrooms. American Educational Research Journal, 34 (2), 365-394. https://doi.org/10.3102/00028312034002365

National Research Council (2000). National Science
Education Standards. Washington, DC: National Academies Press. http://dx.doi.org/1 10.17226/10038

Perkins, D.N., Salomon, G. (1989). Are cognitive skills context-bound? Educational Researcher, 18, 16-25. https://doi. org/10.3102/0013189X018001016

Piaget, J. (1986). Theory of Piaget / History of Foreign Psychology $30^{\text {th }}-60^{\text {th }}$ years. M. 344.

Saenz, G.D., Geraci, L., Miller, T.M., Tirso, R. (2017). Metacognition in the classroom: The association between students' exam predictions and their desired grades. Consciousness and Cognition, 51, 125-139. https://doi.org/10.1016/j.concog.2017.03.002

Schaffer, V. (2017). Enhancing learning to diverse cohorts via immersive visualization. Journal of Hospitality, Leisure, Sport \& Tourism Education, 21(2), 46-54. https://doi.org/10.1016/j.jhlste.2017.07.001

Schraw, G., Dennison, R.S. (1994). Assessing metacognitive awareness. Contemporary Educational Psychology, 19, 460-475. https://doi. org/10.1006/ceps.1994.1033 